\title{
Flutuações temporal e espacial de abundância e composição de tamanho de Aegla castro Schmitt (Crustacea, Anomura, Aeglidae) no Buraco do Padre, Ponta Grossa, Paraná, Brasil ${ }^{1}$
}

\author{
Bianca de Paula Swiech-Ayoub ${ }^{2,3}$ \\ Setuko Masunari ${ }^{2}$
}

\begin{abstract}
Temporal and spatial fluctuation of abundance and size composition of Aegla castro Schmitt (Crustacea, Anomura, Aeglidae) from Buraco do Padre, Quebra-Perna River, Ponta Grossa, Paraná State, Brazil. A study of the annual abundance fluctuation, temporal distribution and size composition of Aegla castro Schmitt, 1942 was carried out at the Buraco do Padre, Quebra-Perna River, Tibagi River Basin, in the municipality of Ponta Grossa, Paraná State. The samplings were done monthly, from February/97 to January/98 with the aid of a hand net and screens at three stations, under an effort of 120 minutes. The average air temperature ranged from $15.0^{\circ} \mathrm{C}$ (May, July, September and October) to $24.3^{\circ} \mathrm{C}$ (December and January), and the water temperature from $15.8^{\circ} \mathrm{C}$ (July) to $22.3^{\circ} \mathrm{C}$ (December). The dissolved oxygen oscillated from $95.7 \%$ (March) to $100.2 \%$ (August) saturation, and the $\mathrm{pH}$ from 6.1 (July) to 7.2 (September). The water flow speed varied from $0.2 \mathrm{~m} / \mathrm{s}$ to $1.2 \mathrm{~m} / \mathrm{s}$. Sulfates and phosphates had values less than $0.2 \mathrm{ppm}$ and the ammonia values alternated from 0.1 to $0.6 \mathrm{ppm}$. A total of 827 specimens were obtained, among which 384 males, 311 females and 132 juveniles. The abundance of Aegla castro varied from 27 (July/97) to 204 (September/97). In the Station 1 higher number and larger specimens were obtained with predominance of males. Juveniles and adults of both sexes occurred in all three sites, but the proportion between juveniles and adults was different. So, these habitats are appropriate to the development of these animals. Males grow up larger than females, due to the reproductive effort of the last ones.

KEY WORDS. Crustacea, Decapoda, Aegla castro, abundance, size composition, Ponta Grossa, Paraná State
\end{abstract}

O gênero Aegla Leach, 1820 é constituído por decápodos anomuros dulcícolas, cuja distribuição geográfica está restrita às regiões subtropical e temperada da América do Sul, abrangendo, integral ou parcialmente, os seguintes países: Argentina, Brasil, Chile, Uruguai, Bolivia e Paraguai (SCHMitT 1942; BAHAMONDE \& LÓPEZ 1961). Atualmente, são conhecidas 61 espécies deste gênero, as quais são registradas desde o município de Franca no Estado de São Paulo, ao norte, até a Ilha de Madre de Dios, Ultima Esperanza, Chile, ao sul (Bond-Buckup \& BuckuP 1994). A maioria das espécies de Aegla não possui uma área de ocorrência muito ampla, vivendo em uma única bacia hidrográfica ou em bacias contíguas ou próximas.

1) Contribuição número 1225 do Departamento de Zoologia, Universidade Federal do Paraná

2) Departamento de Zoologia, Universidade Federal do Paraná. Caixa Postal 19020 , 81531-990 Curitiba, Paraná, Brasil. E-mail: setmas@bio.ufpr.br.

3) Curso de Pós-graduação em Ciências Biológicas, Zoologia. Departamento de Zoologia, Universidade Federal do Paraná. Caixa Postal 19020, 81531-990 Curitiba, Paraná, Brasil Bolsista da CAPES. 
Aegla castro Schmitt, 1942 tem distribuição geográfica restrita do sul do Estado de São Paulo, no município de Itatinga, até o Segundo Planalto do Estado do Paraná, no município de Ponta Grossa. A espécie é registrada neste estado em Curitiba, Londrina, Castro e Ponta Grossa. Neste último município, há registro no Ribeirão Quebra-Perna, um afluente do Rio Tibagi, na Represa dos Alagados e no Rio São Miguel (Bond-BUCKUP \& BUCKUP 1994).

A maior parte dos trabalhos sobre estes caranguejos está restrita ao âmbito da sistemática, distribuição geográfica e relações filogenéticas (ver revisão em BOND-BUCKUP \& BUCKUP 1994). Exceções feitas aos trabalhos de MOUCHET (1932), LÓPEZ \& SAWAYA (1960), BAHAMONDE \& LóPEZ (1961), LóPEZ (1965), RODRIGUES \& HEBLING (1978), BUENO \& BOND-BUCKUP (1996), BUENO \& BOND-BUCKUP (2000) e BUENO et al. (2000), pouco se apurou sobre a ecologia e biologia das espécies de Aegla em seu ambiente natural.

O presente trabalho propõe um estudo descritivo de uma população de Aegla castro no Buraco do Padre, localizado no Rio Quebra-Perna, Bacia do Rio Tibagi, com o objetivo de acrescentar conhecimentos sobre a biologia e ecologia desta espécie.

\section{Descrição da área de estudo}

O Buraco do Padre está situado no Segundo Planalto dos Campos Gerais, numa altitude de aproximadamente 975 m, na Fazenda "Nasce o Dia", município

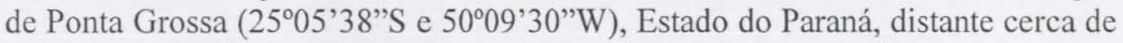
$100 \mathrm{~km}$ a oeste de Curitiba.

Este planalto é banhado pelos tributários da Bacia do Rio Tibagi, que é o principal afluente do Rio Paranapanema. O Rio Tibagi tem suas nascentes nos Campos Gerais, com percurso de aproximadamente $550 \mathrm{Km}$ e, juntamente com o Rio Iapó, forma a Bacia Hidrográfica do Rio Tibagi com $25.239 \mathrm{Km}^{2}$ de área (MAACK 1968).

O Buraco do Padre, situa-se no Rio Quebra-Perna, um afluente do lado direito (leste) do Rio Tibagi, entre a cidade de Tibagi e o Salto Mauá. O Rio Quebra-Perna tem suas nascentes próximas da Invernada Cambiju, uma localidade de Ponta Grossa, a partir da qual se estende por aproximadamente $23,9 \mathrm{Km}$ até desaguar no Rio Tibagi.

Localizado num dos pontos mais altos da região, o Buraco do Padre é uma formação geológica com características entre uma gruta e uma furna. Sua parede rochosa tem aproximadamente $18 \mathrm{~m}$ de altura. No seu quarto superior possui uma abertura por onde recebe um manancial de água-doce na forma de uma queda de água de aproximadamente 16 metros. No assoalho da formação, há um reservatório natural de águas claras sobre um fundo arenoso igualmente claro, de aproximadamente 78 a $314 \mathrm{~m}^{2}$ e de 20 a $60 \mathrm{~cm}$ de profundidade, dependendo da pluviosidade. $\mathrm{O}$ curso de água segue terreno abaixo sobre um leito de seixos, pedregulhos e matacões entremeados com areia, com largura de cerca de 5 a 8 metros e profundidade de 20 a $40 \mathrm{~cm}$. Fora do Buraco do Padre, a corredeira é margeada em ambos os lados por uma mata ciliar.

Devido à sua beleza arquitetônica natural, o Buraco do Padre constitui um dos vários pontos turísticos da região, estando aberto à visitação pública. 


\section{MATERIAL E MÉTODOS}

Foram estabelecidos três pontos de coleta: um no reservatório natural junto à queda de água no interior do Buraco do Padre (Estação I) e dois na corredeira ao longo do riacho distantes da Estação I cerca de 250 m (Estação II) e 300 m (Estação III), respectivamente.

A coleta de dados bióticos e abióticos foi realizada mensalmente de fevereiro/97 a janeiro/98. As variáveis abióticas registradas foram: temperatura do ar, $\mathrm{pH}$, temperatura e porcentagem de saturação de oxigênio na água, velocidade da água (tomada conforme metodologia de JoHN 1978) e observação visual do tempo por ocasião da coleta. A salinidade foi medida na primeira coleta com um refratômetro e, após constatada salinidade nula, ela não foi medida nas demais. Destas variáveis, foram obtidas as médias aritméticas dos valores obtidos nas três estações de coleta.

$\mathrm{Na}$ Estação I, os animais foram coletados manualmente com auxílio de peneiras e puçás com rede de $2 \mathrm{~mm}$ de abertura de malha e o esforço de coleta consistiu na procura de aeglídeos em toda a área do reservatório por 120 minutos. Nas Estações II e III, os caranguejos foram obtidos por revolvimento manual dos seixos, pedregulhos e folhas submersas, os quais foram recolhidos em um puçá posicionado contra o próprio fluxo de água. O esforço de coleta foi de 60 minutos, numa área entre $100 \mathrm{e} 160 \mathrm{~m}^{2}$. Os animais foram triados, mensurados e sexados in loco e, após, liberados em conjunto ao hábitat de origem. A abundância animal foi expressa em taxa de captura por tempo de coleta (120 minutos). Portanto, os dados relativos às Estações II e III foram convertidos para este tempo de esforço de coleta.

Os dados morfométricos foram obtidos em milímetros com um paquímetro de $0,01 \mathrm{~mm}$ de precisão, e consistiram na medida do tamanho do animal em termos de comprimento da carapaça, da ponta do rostro até o seu bordo posterior.

A sexagem foi feita baseada na presença dos quatro pares de pleópodos no abdome das fêmeas e ausência destes nos machos. O menor indivíduo apresentando pleópodos visíveis, portanto, uma fêmea, mediu $6,5 \mathrm{~mm}$ de comprimento da carapaça. Os exemplares com tamanhos inferiores a este foram considerados juvenis, pois, nestes, os caracteres sexuais secundários não eram visíveis com a metodologia utilizada.

No estudo da estrutura populacional, os animais foram distribuídos em 14 classes de comprimento da carapaça com intervalo de $2,0 \mathrm{~mm}$. Os limites para juvenis foram: classe $\mathrm{A}: 2,5 \leftrightarrow 4,4 \mathrm{~mm}$; e classe $\mathrm{B}: 4,5 \leftrightarrow 6,4 \mathrm{~mm}$ e para adultos, classe C: $6,5 \leftrightarrow 8,4 \mathrm{~mm}$; classe D: $8,5 \leftrightarrow 10,4 \mathrm{~mm}$; classe E: $10,5 \leftrightarrow 12,4 \mathrm{~mm}$; classe F: $12,5 \leftrightarrow 14,4 \mathrm{~mm}$; classe G: $14,5 \leftrightarrow 16,4 \mathrm{~mm}$; classe $\mathrm{H}: 16,5 \leftrightarrow 18,4 \mathrm{~mm}$; classe I: $18,5 \leftrightarrow 20,4 \mathrm{~mm}$; classe J: $20,5 \leftrightarrow 22,4 \mathrm{~mm}$; classe $\mathrm{K}: 22,5 \leftrightarrow 24,4 \mathrm{~mm}$; classe L: $24,5 \leftrightarrow 26,4 \mathrm{~mm}$; classe M: $26,5 \leftrightarrow 28,4 \mathrm{~mm}$ e classe N: $28,5 \leftrightarrow 30,4$ $\mathrm{mm}$. A freqüência nas classes foi calculada agrupando os dados trimestralmente.

Para o estudo da distribuição espacial dos animais foi testada a hipótese de nulidade na proporção de machos, fêmeas e juvenis entre as três estações de coleta através do teste de Qui-quadrado para uma amostra, com um grau de liberdade a 95\% de nível de confiança (SIEGEL 1981). 


\section{RESULTADOS}

A temperatura média mínima do ar nos dias das coletas foi de $15^{\circ} \mathrm{C}$ registrada em maio, julho, setembro e outubro/97 e a máxima de $24,3^{\circ} \mathrm{C}$ em dezembro/97 e janeiro/ 98 , com uma amplitude de $9,3^{\circ} \mathrm{C}$ (Fig. 1). A temperatura média da água variou de $15,8^{\circ} \mathrm{C}$ a $22,3^{\circ} \mathrm{C}$ registradas, respectivamente, em julho/97 e dezembro/97, com uma amplitude de $6,5^{\circ} \mathrm{C}$ (Fig. 1 ).
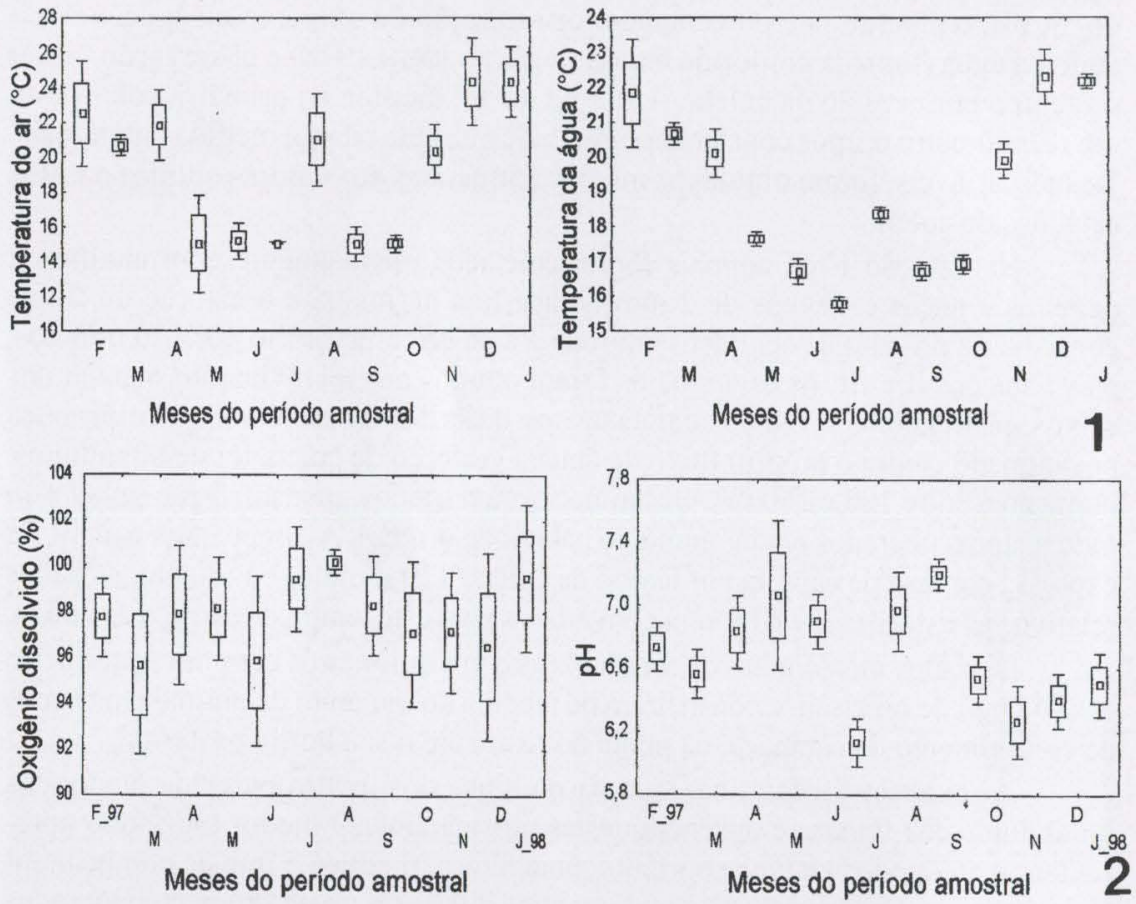

Figs 1-2. Buraco do Padre. Amplitude de variação, erro padrão e média das (1) temperaturas do ar, da água e da (2) porcentagem de saturação de oxigênio e do $\mathrm{pH}$ da água, nas três estações de coleta durante o período amostral.

Em agosto, houve uma elevação excepcional da temperatura do ar, mas, de um modo geral, estes valores foram menores na Estação I quando comparadas com as outras duas. Em contraste, as temperaturas da água não mostraram grande variação entre as estações de coleta, com exceção do mês de fevereiro, quando a amplitude de variação foi de $3^{\circ} \mathrm{C}$, tendo a mais baixa registrada, também, na Estação I.

Durante o período de coleta, o valor mínimo de saturação de oxigênio na água foi de 95,7\% (março/97) e o máximo de 100,2\% (agosto/97); na Estação I foram registrados os maiores valores (Fig. 2). No presente estudo, não houve correlação significativa entre a flutuação desta variável e a da temperatura da água. Tampouco o tempo por ocasião da coleta esteve relacionado com as mesmas. 
A flutuação mensal média do pH nos dias de coleta variou de 6,1 (julho/97) a 7,2 (setembro/97). Na Estação I, estes valores foram superiores ou iguais às Estações II e III, com exceção dos meses de março e abril/97. Entretanto, a diferença de $\mathrm{pH}$ entre as estações de coleta não ultrapassou a unidade (0,9) (Fig. 2). O tempo por ocasião da coleta foi bom em seis dos doze meses de coleta, nublado em cinco meses e chuvoso somente em junho/97.

A velocidade do curso da água variou de $0,20 \mathrm{~m} \cdot \mathrm{s}^{-1}$ a $1,20 \mathrm{~m} \cdot \mathrm{s}^{-1}$. As maiores velocidades foram registradas na corredeira propriamente dita (Estações II e III) e caracterizaram o local como intermediário entre águas lentas e rápidas, o que é típico de canais com leitos tortuosos e irregularidades morfológicas, cujo fluxo da água é turbulento.

Foi capturado, um total de 827 indivíduos, dos quais 384 machos, 311 fêmeas e 132 juvenis. Os machos perfizeram $46 \%$ da população amostrada, as fêmeas $38 \%$ e os juvenis $16 \%$.

A abundância de Aegla castro, convertida para o tempo de 120 minutos de coleta, variou mensalmente de 29 (julho/97) a 204 (setemtro/97).

Houve dois picos na flutuação de abundância: o primeiro em março/97, menos acentuado, com 158 exemplares e o segundo em setembro/97 com 204. Baixos valores de abundância ocorreram em fevereiro (46), julho (29) e novembro (42).

Em setembro, foram amostrados apenas adultos ( $48 \%$ machos e $52 \%$ fêmeas), os quais ocasionaram o segundo pico na curva de flutuação de abundância. $\mathrm{O}$ pico de março teve influência de fêmeas (45\%), machos (35\%) e juvenis $(20 \%)$. Em abril, os juvenis (64) ultrapassaram o número de machos e fêmeas (52), porém em maio nenhum juvenil foi amostrado. Os adultos estiveram presentes durante todo o período amostral (Fig. 3).

Ao longo dos 12 meses, foi coletado um total de 458 indivíduos na Estação I, enquanto que nas Estações II e III, respectivamente, 200 e 169. Em termos de abundância padronizada para um esforço de 120 minutos, foram 458 espécimes na Estação I, 400 na II e 338 na III. Foi significativa a diferença no número de espécimes coletados entre as Estações I e III $\left(x^{2}(3,84)=9,04\right)$. Houve juvenis e adultos em todos os subsistemas (Fig. 4).

$\mathrm{Na}$ Estação I, foram registrados os seguintes valores em abundância: 230 machos, 169 fêmeas e 59 juvenis. Na Estação II, 168 machos, 160 fềmeas e 72 juvenis, enquanto que na Estação III, 140 machos, 124 fêmeas e 74 juvenis. De modo geral, houve uma tendência ao declínio na abundância de machos e fêmeas da Estação I para a Estação III, ao passo que para os juvenis, a tendência foi para um incremento (Fig. 4). Entretanto, estatisticamente, apenas na Estação I a diferença numérica entre machos e fêmeas foi significativa $\left(x^{2}(3,84)=4,83\right)$; fêmeas e machos predominam sobre os juvenis nas três Estações $\left(x^{2}(3,84)\right.$ entre 6,3 e 50,6$)$, sendo que a diferença é maior entre machos e juvenis e entre a Estação I e as II e III.

Comparando-se a abundância total de machos, fêmeas e juvenis entre as três estações de coleta, foi constatado que não há diferença significativa entre o número de juvenis e fêmeas. Porém, dentre os machos, a Estação I mostrou valor significativamente maior quando comparada com as Estações II e III $\left(x^{2}(3,84)=4,83\right.$ e 10,9 respectivamente). 

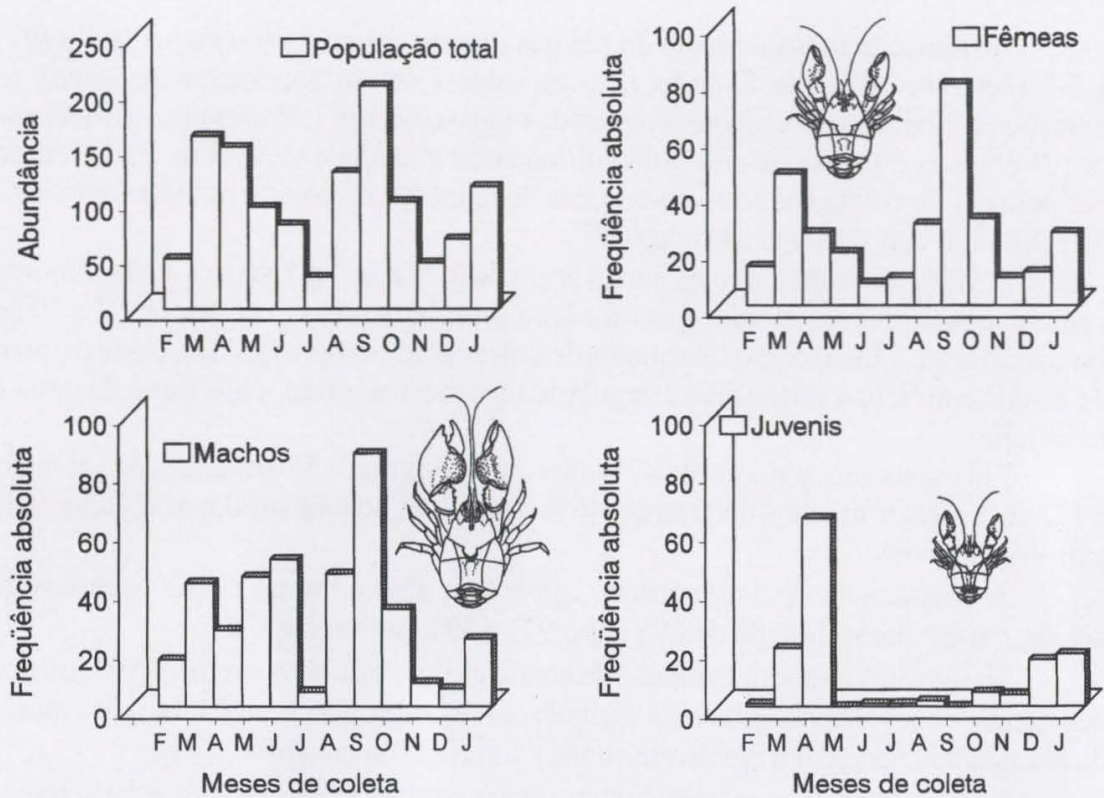

Fig. 3. Aegla castro. Flutuação anual da abundância da população (convertida para 120 minutos de esforço amostral) e do número absoluto de machos, fêmeas e juvenis registrados ao longo do periodo amostral

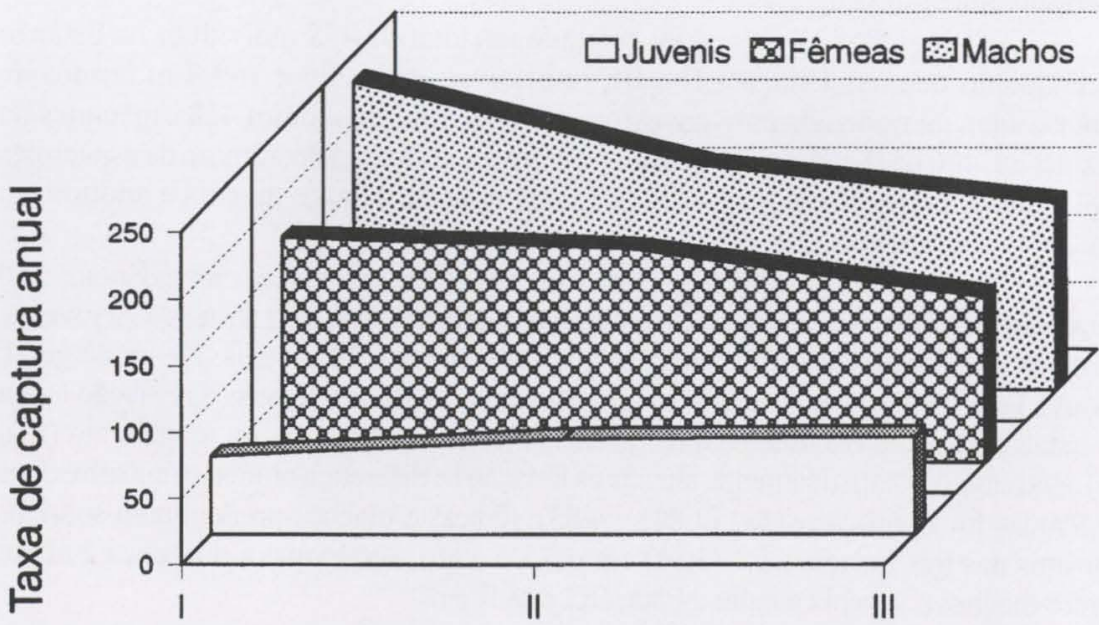

Estações de coleta

Fig. 4. Aegla castro. Taxa de captura anual de machos, fêmeas e juvenis nas três estações de coleta. 
O comprimento da carapaça da população teve uma amplitude de variação de $26,4 \mathrm{~mm}$, com limite inferior de $3,1 \mathrm{~mm}$ e superior de $29,5 \mathrm{~mm}$. A amplitude de tamanho entre os juvenis foi de 3,1 (abril) a $6,4 \mathrm{~mm}$ (dezembro), entre as fêmeas e os machos foi, respectivamente, de 6,5 (março) a $27,6 \mathrm{~mm}$ (abril) e 6,5 (janeiro) a $29,5 \mathrm{~mm}$ (maio).

A figura 5 mostra a distribuição da abundância de juvenis, machos e fêmeas nas classes de comprimento da carapaça, nas três estações de coleta, durante o periodo estudado. Houve um decréscimo no número de classes de tamanho nas amostras da Estação I para a Estação III.

Na Estação I, a população encontra-se distribuída desde a classe $\mathrm{A}$ até $\mathrm{N}$. Os machos formam uma população com distribuição bimodal, com predominância de indivíduos das classes E, G, H e I. As fêmeas foram mais abundantes nas classes E e I. Na Estação II, houve representantes das classes A até M, entretanto, a parcela adulta da população mostrou uma tendência à queda na freqüência de indivíduos de maior porte. Entre os machos predominaram indivíduos na classe $\mathrm{E}$ e entre as fêmeas na classe C. Na Estação III, houve indivíduos nas classes A a $\mathrm{L}$ e os adultos (machos e fêmeas) foram mais freqüentes na classe $\mathrm{E}$ (Fig. 5). Desta forma, animais maiores foram mais freqüentes na Estação I, enquanto nas demais, foram menos freqüentes, e os juvenis mostraram distribuição quase eqüitativa entre as três estações.

Os machos apresentaram comprimento médio da carapaça de $15,3 \mathrm{~mm}$ ao longo do período de estudo, enquanto que as fêmeas e juvenis 14,1 e $5,1 \mathrm{~mm}$, respectivamente (Tab. I). Houve diferença significativa entre o comprimento médio da carapaça de machos e fêmeas nos meses de maio $(t=2,25 ; \mathrm{p}=0,027)$, setembro $(t=2,0 ; p=0,046)$, outubro $(t=3,80 ; p=0,0003)$ e dezembro $(t=2,73 ; p=0,014)$, onde os machos apresentaram as maiores médias.

Tabela I. Aegla castro. Comprimento médio mensal da carapaça $(\mathrm{mm})$ de machos, fêmeas e juvenis. (N) Número amostral, (C.V.) coeficiente de variação.

\begin{tabular}{|c|c|c|c|c|c|c|c|c|c|}
\hline \multirow[t]{2}{*}{ Meses de coleta } & \multicolumn{3}{|c|}{ Machos } & \multicolumn{3}{|c|}{ Fêmeas } & \multicolumn{3}{|c|}{ Juvenis } \\
\hline & $n$ & Média & C.V. & $n$ & Média & C.V. & $n$ & Média & C.V. \\
\hline Fevereiro/1997 & 16 & 15,2 & 43,1 & 14 & 16,6 & 36,6 & 1 & 4,7 & - \\
\hline Março/1997 & 42 & 12,7 & 43,2 & 47 & 12,7 & 41,9 & 20 & 5,4 & 14,3 \\
\hline Abril/1997 & 26 & 14,5 & 36,2 & 26 & 13,3 & 38,1 & 64 & 4,9 & 17.3 \\
\hline Maio/1997 & 44 & 14,8 & 42,1 & 19 & 11,3 & 35,7 & - & - & - \\
\hline Junho/1997 & 50 & 11,4 & 33,0 & 8 & 13,4 & 40,4 & 1 & 3,8 & - \\
\hline Julho/1997 & 5 & 13,4 & 29,2 & 10 & 13,7 & 28,2 & 1 & 3,3 & - \\
\hline Agosto/1997 & 45 & 16,6 & 28,9 & 29 & 15,5 & 24,3 & 2 & 5,9 & 1,2 \\
\hline Setembro/1997 & 86 & 15,8 & 25,3 & 79 & 14,6 & 24,1 & - & - & - \\
\hline Outubro/1997 & 33 & 19,3 & 21,8 & 31 & 15,7 & 22,1 & 5 & 3,5 & 8,9 \\
\hline Novembro/1997 & 8 & 18,5 & 19,8 & 10 & 15,9 & 25,5 & 4 & 5,3 & 9,6 \\
\hline Dezembro/1997 & 6 & 18,6 & 13,5 & 12 & 13,6 & 19,3 & 16 & 5,2 & 16,5 \\
\hline Janeiro/1998 & 23 & 12,1 & 55,8 & 26 & 12,3 & 45,1 & 18 & 5,3 & 12,1 \\
\hline Total & 384 & 15,3 & 34,2 & 311 & 14,1 & 32,4 & 132 & 5,1 & 17.4 \\
\hline
\end{tabular}

Na distribuição de freqüência de machos e fêmeas nas classes de comprimento da carapaça (Fig. 6) observou-se no primeiro trimestre (fevereiro/março/abril), dois grupos etários para a população de Aegla castro. O primeiro abrangeu 

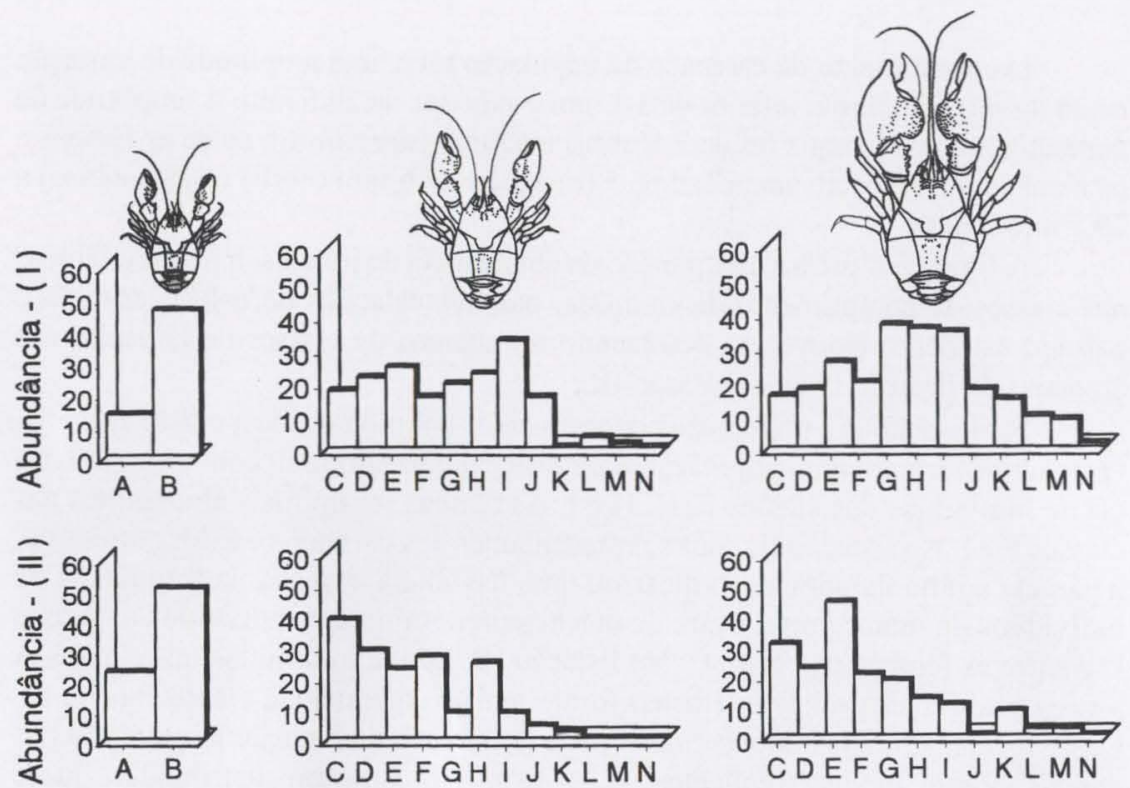

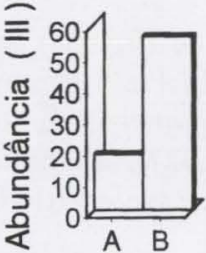

Juvenis

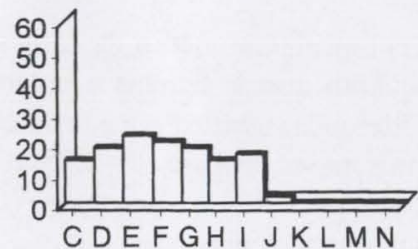

Fêmeas

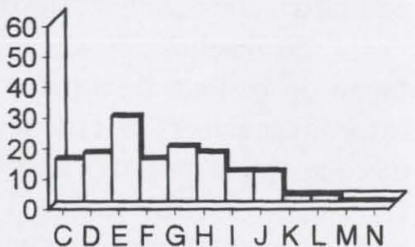

Machos

Classes de comprimento da carapaça

Fig. 5. Aegla castro. Distribuição de juvenis, machos e fêmeas nas classes de comprimento da carapaça nas três estações de coleta, durante o período amostral. (A) $2,5 \leftrightarrow 4,4 \mathrm{~mm}$; (B) $4,5 \leftrightarrow 6,4 \mathrm{~mm}$; (C) $6,5 \leftrightarrow 8,4 \mathrm{~mm}$; (D) $8,5 \leftrightarrow 10,4 \mathrm{~mm}$; (E) $10,5 \leftrightarrow 12,4 \mathrm{~mm}$; (F) $12,5 \leftrightarrow 14,4$ mm; (G) $14,5 \leftrightarrow 16,4 \mathrm{~mm}$; (H) 16,5↔18,4 mm; (I) $18,5 \leftrightarrow 20,4 \mathrm{~mm}$; (J) $20,5 \leftrightarrow 22,4 \mathrm{~mm}$; (K) $22,5 \leftrightarrow 24,4 \mathrm{~mm}$; (L) $24,5 \leftrightarrow 26,4 \mathrm{~mm}$; (M) $26,5 \leftrightarrow 28,4 \mathrm{~mm}$; (N) $28,5 \leftrightarrow 30,4 \mathrm{~mm}$.

machos e fêmeas até aproximadamente a classe $\mathrm{F}$ e o segundo as demais classes. Neste trimestre, o recrutamento de juvenis ocorreu de forma apreciável. No segundo trimestre (maio/junho/julho), embora discretamente, o recrutamento teve continuidade com novos indivíduos na população de machos e fêmeas. Também, houve um deslocamento modal dos dois grupos etários observados no trimestre anterior em ambos os sexos, sendo este deslocamento mais aparente no primeiro grupo. No trimestre agosto/setembro/outubro, o recrutamento continuou, mas, de alguns poucos juvenis na população de machos e fêmeas e o grupo mais velho verificado no primeiro trimestre começou a diminuir em freqüência, principalmente das fêmeas; observou-se ainda o deslocamento modal dos outros dois grupos etários verificados 
no trimestre anterior, e o aparecimento de um novo grupo etário. No último trimestre (novembro/dezembro/janeiro), o recrutamento de novos indivíduos na população ocorreu com grande intensidade, e o grupo etário mais velho verificado no primeiro trimestre desapareceu. $\mathrm{O}$ deslocamento modal dos outros grupos etários continuou. Os juvenis foram mais abundantes no primeiro e no quarto trimestres. A velocidade de deslocamento modal dos machos tem ligeira vantagem sobre o das fêmeas e as classes de tamanho maiores são formadas quase que exclusivamente por machos.

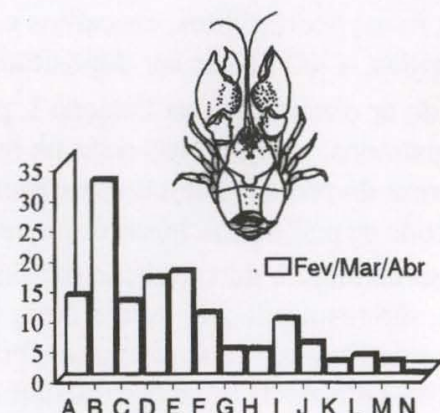

A B CDEFGH I J KLMN
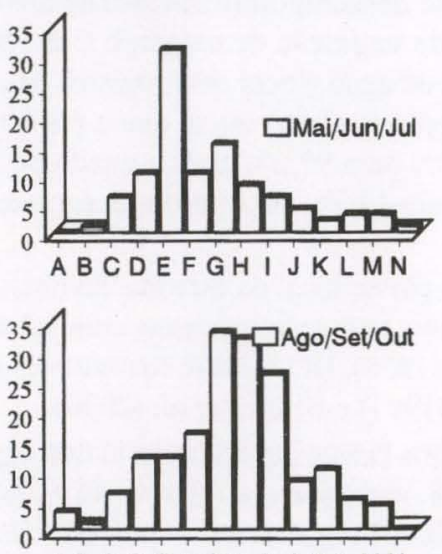

A B C DEFGH I JKL MN

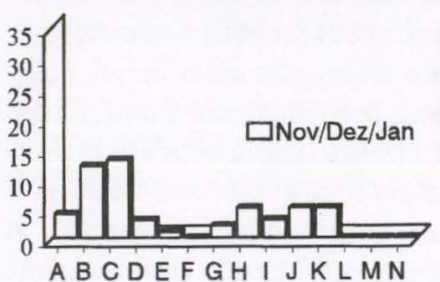

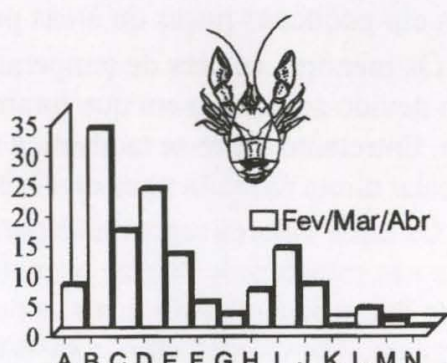

A B C DEFGH I J K L M N
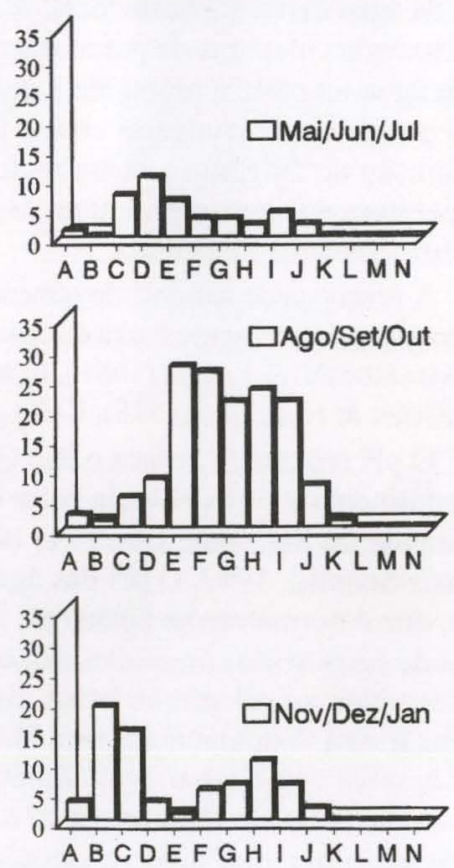

Classes de comprimento da carapaça

Fig. 6. Aegla castro. Distribuição de freqüência absoluta de machos (coluna à esquerda) e fêmeas (coluna à direita) nas classes de comprimento da carapaça (ver legenda na figura anterior). 


\section{DISCUSSÃO}

Segundo SCHÄFER (1985), o Rio Quebra-Perna pode ser caracterizado climaticamente como um rio eurréico, permanente e superficial. O seu regime hidrológico é do tipo simples pluvial tropical, sendo a vazão dependente da distribuição anual das épocas de chuva e de seca. O local de coleta no referido rio é caracterizado como região Ritral, cuja temperatura média mensal da água está próxima de $20^{\circ} \mathrm{C}$; a velocidade é relativamente alta e o volume do fluxo é pequeno; o substrato é composto de rochas fixas, pedregulhos, cascalhos e areia. Apenas em pequenas poças ou áreas protegidas, o lodo pode ser depositado.

Os menores valores de temperatura do ar observados na Estação I, podem ter sido devido ao horário em que foram registrados, sempre mais cedo na referida estação. Entretanto, deve-se também, à natureza do próprio hábitat que é protegido da luz solar direta na maior parte do dia e cercado de paredes rochosas muito úmidas.

Os altos valores registrados para a porcentagem de saturação de oxigênio da água nas estações de coleta, certamente, são resultados da temperatura relativamente baixa da água e do fluxo turbulento do rio que favorecem a solubilidade do oxigênio. Os valores altos registrados na Estação $\mathrm{I}$, devem-se justamente à queda de água existente neste local. A favor desta hipótese, no mês de novembro, foram tomadas medidas de porcentagem de saturação de oxigênio e da temperatura da água na parte à montante à queda de água (local sem registro de Aegla), com o propósito de comparar com a Estação I: observou-se que a porcentagem de saturação de oxigênio aumentou de $94 \%$ para $99,2 \%$ após a queda de água, e a temperatura da água diminuiu de 23,2 para $19,7^{\circ} \mathrm{C}$ no interior da formação que constitui a Estação I de coleta.

A presença de animais do gênero Aegla no local de estudo é favorecida pela temperatura relativamente baixa da água e alto teor de oxigenação, como observado por BAHAMONDE \& LÓPEZ (1961), LÓPES (1965), HEBLING \& RODRIGUES (1977), Rodrigues \& HEBling (1978), CHALAR (1994) e Bueno et al. (2000).

$\mathrm{O}$ pH registrado coloca o Rio Quebra-Perna entre a maioria dos corpos de água continentais cujo $\mathrm{pH}$ varia entre 6 e 8 , inclusive o do Arroio do Mineiro, no Rio Grande do Sul, onde BUENo et al. (2000) registraram populações de Aegla platensis Schmitt, 1942. O pH das águas lóticas continentais é influenciado pela chuva, que é normalmente ácida ( $\mathrm{pH}$ 5-6) (ESTEVES 1988) e que carrega para os corpos de água ácidos orgânicos dissolvidos de origem alóctone. A interferência de seres vivos no $\mathrm{pH}$ parece baixa, devido à renovação constante da água. Esta inferência está fundamentada em MAIER (1978), que considera a precipitação pluviométrica como a variável climática mais importante nos trópicos. Ela atua sobre a concentração de nutrientes, íons em geral e matéria orgânica, alterando não apenas o $\mathrm{pH}$, mas ainda a velocidade da corrente dos rios, a quantidade de oxigênio dissolvido, a turbidez e outros fatores físico-químicos importantes para os seres vivos.

Segundo FITTKAU (1976 apud SCHÄFER 1985), o rio é uma seqüência de ecossistemas e para ODUM (1971) as comunidades estão caracterizadas pelo intercâmbio energético ou de nutrientes em distintos níveis tróficos. O Ritroceno como 
um ecossistema é subdividido em hábitats como Ritrobental, Ritropelagial e Ritroquinal (SCHÄFER 1985). A espécie em estudo, Aegla castro, é componente da comunidade do Ritrobental. No curso superior do rio (Crenoceno e Ritroceno), não há condições para que se realize uma produção primária autóctone suficiente e as comunidades que vivem dos poucos nutrientes alóctones são, na maioria, predadores, como Aegla castro que se alimenta de larvas, bem como de adultos de insetos que porventura caiam na água.

Aegla castro, no presente estudo, foi encontrada no fundo do rio, sob pedregulhos, bem como próximo às margens, oculta sob restos de vegetação e sob raizes e troncos caídos. Alguns exemplares foram coletados sobre rochas, acima do nível da água, o que estaria relacionado segundo RoDRIGUES \& HEBLING (1978) com a procura de alimento. Ao contrário do constatado por BAHAMONDE \& LÓPEZ (1961), que não encontraram Aegla em fundos de muita sedimentação, no presente trabalho, grande número foi capturado na Estação I, onde o fundo é arenoso mas desprovido de pedregulhos ou cascalhos. Folhas mortas submersas serviram de principal abrigo nesta estação.

Adultos e juvenis apresentaram tendências gregárias, como observado por BAHAMONDE \& LÓPEZ (1961), LÓPEZ (1965) e RODRIGUES \& HEBLING (1978), os quais se agrupavam em locais sombreados e protegidos da forte correnteza sob abrigos como folhas submersas, troncos caídos, pedregulhos ou raízes dos vegetais que se encontram nas margens da corredeira.

Os picos na curva de flutuação da população de Aegla castro não estão relacionados com a flutuação anual da temperatura, já que eles ocorreram tanto em temperatura baixa (outono), quanto em temperaturas mais elevadas (primavera). O pico observado em abril está, provavelmente, relacionado ao principal período de recrutamento de juvenis, enquanto que o de setembro, com o período reprodutivo da espécie. O mesmo observa-se com relação à redução na abundância. Esta pode estar ligada às atividades comportamentais e às mortalidades. Para Aegla platensis, Schmitt, 1942, também, a temperatura não foi o fator primordial na flutuação de sua densidade no Arroio do Mineiro, Rio Grande do Sul, tendo os autores sugerido a migração dos animais como um dos prováveis fatores (BUENO et al. 2000).

A presença de juvenis durante quase todos os meses de amostragem permite inferir que a espécie se reproduz o ano inteiro (SWIECH-AYOUB \& MASUNARI 2001) e, este comportamento reprodutivo parece ser comum dentre os Aeglidae, a exemplo das populações de Aegla platensis estudadas por BUENO \& BOND-BUCKUP (2000) no Arroio do Mineiro, Rio Grande do Sul.

O fato dos adultos serem mais abundantes que os juvenis, nos três pontos de coleta, não significa necessariamente que eles realmente constituam a maioria. A baixa abundância de juvenis nas amostragens pode ter sido um reflexo da dificuldade em capturá-los. A longevidade da espécie, estimada em aproximadamente dois anos não seria o suficiente para proporcionar uma estrutura dominada por organismos mais velhos, e sim por juvenis. Baseando-se na fecundidade das fêmeas de Aegla longirostris (90 a 204 ovos e número médio de 121,36 \pm 31 ,66, segundo R.C.F. 
Cardoso, comunicação pessoal), e supondo que a fecundidade de Aegla castro seja próxima deste valor, reforça a hipótese de que os juvenis constituiriam a maioria. Esta condição é necessária para a manutenção da população local, pois, escassez de juvenis aliada a uma sobrevida relativamente curta, culminaria na extinção da espécie.

A predominância de machos na população Aegla castro foi observada, também, em Aegla platensis (BUENO \& BOND-BUCKUP 2000; BUENO et al. 2000), o que pode ser um reflexo das diferenças comportamentais entre os sexos. Esta inferência está baseada na observação em laboratório que, fêmeas ovígeras procuram abrigo dentro da camada de pedregulhos, o que teria dificultado a sua captura. Além disso, este fato pode estar relacionado com a maior longevidade dos machos de Aegla castro, pois, quase sempre, estes foram os representantes mais numerosos das classes de maior comprimento da carapaça (Fig. 5). Este fenômeno é muito comum dentre os Crustacea, a exemplo do Porcellanidae Petrolisthes armatus (Gibbes, 1850) (OliveIRA \& MASUNARI 1995).

A dominância numérica de Aegla castro na Estação I pode estar relacionada com a peculiaridade da arquitetura do hábitat. Embora neste local haja complexidade menor de substrato (ausência de pedregulhos ou cascalhos, troncos caídos, raízes de vegetais) em relação às Estações II e III, a presença da queda de água com mais de 13 metros de altura constitui uma barreira para a migração desta população rio acima, incrementando a abundância nesta estação. A favor desta hipótese, não foi observado qualquer caranguejo no reservatório localizado logo acima da referida queda de água. O registro de Aegla castro no Rio Tibagi (BOND-BUCKUP \& BUCKUP 1994), do qual o Rio Quebra-Perna é afluente, permite uma especulação que teria seguido contra a corrente até o Buraco do Padre.

Na Estação I, os abrigos dos caranguejos consistiram basicamente de manchas de serapilheira submersa extremamente instável, mudando continuamente de posição ou até mesmo deixando de existir, quando carreados pelas chuvas torrenciais e pela agitação da água provocada pela cachoeira. Por outro lado, em condições de estiagem, a velocidade da água é muito baixa neste local (variou de 0,13 até $0,48 \mathrm{~m} / \mathrm{s}$ ), enquanto que nas Estações II e III é relativamente alta (variou de 0,43 até $1,20 \mathrm{~m} / \mathrm{s}$ ) e, nestes últimos locais, os abrigos são abundantes e mais estáveis, embora limitados à área marginal. Estes abrigos parecem fundamentais para a existência da parcela de juvenis da população destes caranguejos (Fig. 4). Embora a diferença na dominância de adultos e juvenis nas estações de coleta não seja estatisticamente significativa, do ponto de vista biológico, os juvenis são mais abundantes na corredeira devido à maior disponibilidade de substrato adequado e estável nas margens do rio. Esta condição é conferida pelo acúmulo de troncos em decomposição, gravetos e serapilheira, e pela diminuição da velocidade do fluxo de água nestes hábitats marginais ( $\mathrm{SCHÄ}$ FER 1985). O coeficiente de variação da Estação I é muito elevado (96\%), da Estação II é intermediário (64\%) e da Estação III é de somente 34\%. Isso pode refletir a maior variabilidade na disponibilidade de refúgios na Estação I. O coeficiente intermediário da Estação II pode indicar os efeitos da passagem dos 
organismos da Estação I para a III. Aparentemente, os juvenis podem ser facilmente arrastados rio abaixo, devido à falta de abrigos na Estação I, principalmente quando recém-eclodidos e/ou após as chuvas.

Devido à multiplicação de substrato pelo acúmulo de material biogênico nas margens do rio, aliada ao hábito gregário da espécie, provavelmente, não há competição por abrigos entre juvenis e adultos de Aegla castro no local de estudo. Entretanto, uma competição por alimento pode existir. A favor desta hipótese, foi observado, em laboratório, que fêmeas adultas praticam canibalismo, por predação de seus juvenis recém-eclodidos.

Na corredeira (Estações II e III), os juvenis provavelmente encontram, além de uma infinidade de abrigos, grande quantidade de larvas aquáticas como fonte de alimento. A forte correnteza pode ser fator limitante para a espécie, a qual procura migrar novamente em direção à Estação I onde a correnteza é mais amena. $\mathrm{Na}$ corredeira, os adultos não atingem abundâncias expressivas nas classes de tamanho maiores, o que pode ser decorrente de uma maior taxa de mortalidade ou emigração destes locais (Fig. 5). Movimentos de caráter migratório foram registrados para Aegla paulensis (LóPEZ 1965) a $32 \mathrm{~km}$ de São Paulo. Através de marcação, observou-se que estes animais realizam migrações de até 300 metros, que podem ser rio acima ou no sentido contrário. São capazes de ultrapassar obstáculos de mais de um metro de altura como pequenas cascatas. No referido trabalho, também, os autores registraram grande quantidade de exemplares pequenos no trecho do arroio e predominância de adultos no reservatório.

No presente trabalho, o reservatório de água (Estação I) funcionou como uma "área fonte" de Aegla castro, que pode estar contribuindo para o povoamento de parcelas rio abaixo, caso ocorra algum desequilíbrio que resulte numa extinção local da espécie nos trechos da corredeira. Portanto, o reservatório consiste num local de importância capital, tendo como ponto de vista a preservação da espécie na área.

O comprimento médio dos machos superou o das fêmeas principalmente no período reprodutivo (maio a outubro), o que pode estar relacionado com o stress conseqüente da postura de ovos nas fềmeas da espécie; estas teriam alocado energia para a produção de ovos em detrimento do crescimento do corpo. BAHAMONDE \& LOPEZ (1961), RoDRIGUES \& HEBLING (1978) e BUENO et. al. (2000) registraram, também, em Aegla laevis laevis, Aegla perobae e Aegla platensis, respectivamente, que machos atingem tamanhos maiores que as fêmeas. Aegla castro apresentou tamanhos máximos para machos $(29,5)$ e fêmeas $(27,6)$ maiores que o observado para Aegla paulensis (22,0 e 19,0 mm), Aegla perobae (25,0 e 23,0 mm) e Aegla platensis (21,0 e 16,8-18,0 mm). Porém, ela pode ser considerada uma espécie de tamanho intermediário uma vez que Aegla parana pode atingir até $52,3 \mathrm{~mm}$ de comprimento de carapaça (BOND-BUCKUP \& BUCKUP 1994).

$\mathrm{O}$ recrutamento ocorrido durante praticamente todo o período amostral e o número reduzido de exemplares capturados em alguns meses dificultaram a visualização das modas. A distribuição de freqüência absoluta dos dados agrupados trimestralmente permitiu detectar o deslocamento modal e mostrou que os machos 
crescem mais rápido que as fêmeas. Esse fato é observado na maioria dos Decapoda, cujas fêmeas, após a maturidade, sofrem longas intermudas, principalmente associadas à postura dos ovos. Como resultado, após a puberdade, as fêmeas usualmente sofrem muda com menos freqüência, crescem mais vagarosamente e atingem tamanhos menores que os machos (HARTNOLL 1985).

Diante da presença de juvenis e adutos de Aegla castro nos diversos microhábitats do Rio Quebra-Perna pode-se predizer, de maneira geral que, o mesmo apresenta condições físico-químicas e biológicas adequadas ao desenvolvimento e reprodução da espécie, ao longo do trecho estudado. O local de estudo por enquanto está protegido da ação antrópica e constitui um hábitat importante para muitas espécies animais e vegetais.

AGRADECIMENTOS. À CAPES na pessoa de seu presidente, pela Bolsa de Mestrado concedida a B.P. Swiech-Ayoub. Ao Sr. Ferdinando Schaeffer, pela permissão do acesso à sua propriedade para execução do presente projeto. À M.Sc. Tereza Cristina Margarido do Museu do Capão da Imbuia, Curitiba, Paraná, pelo auxílio no trabalho de curadoria para identificação de Aegla castro. Ao Prof. Naldy Emerson Canali e Fabrizia Gioppo Nunes, do Departamento de Geografia, UFPR, pelos dados fornecidos acerca da extensão e nascente do Rio Quebra-Perna. Aos Profs Paulo Ricardo Pezzuto e José Marcelo Aranha pela leitura crítica do trabalho. Às colegas de trabalho Claudia Regina Bosa, Edinalva Oliveira e Bárbara Stremel Ribeiro pelo auxilio nos trabalhos de coleta do material biológico e obtenção dos dados biométricos.

\section{REFERÊNCIAS BIBLIOGRÁFICAS}

B^hАmonde, N.N. \& M.T. López. 1961. Estudios biológicos en la población de Aegla laevis laevis (Latreille) de El Monte (Crustacea, Decapoda, Anomura). Invest. Zool. Chil., Santiago, 7: 19-58. BOND-BUCKUP G. \& L. BuCKUP. 1994. A família Aeglidae (Crustacea, Decapoda, Anomura) Arq. Zool., São Paulo, 32 (4): 159-346.

Bueno, A.A.P. \& G. Bond-Buckup. 1996. Os estágios juvenis iniciais de Aegla violacea Bond-Buckup \& Buckup (Crustacea, Anomura, Aeglidae) Nauplius 4: 39-47.

- 2000. Dinâmica populacional de Aegla platensis Schmitt (Crustacea, Decapoda, Aeglidae). Revta bras. Zool. 17 (1): 43-49.

Bueno, A.A.P.; G. Bond-Buckup \& L. Buckup. 2000. Crescimento de Aegla platensis Schmitt em ambiente natural (Crustacea, Decapoda, Aeglidae). Revta bras. Zool. 17 (1): 51-60.

ChalAR, G. 1994. Zoobenthic composition and abundance in the Arroyo Toledo (Uruguay), and its relation with the water quality. Rev. Chil. Hist. Nat. 67 (2):129-141.

Esteves, F. A. 1988. Fundamentos de Limnologia. Rio de Janeiro, Interciência, 575p.

HARTNOLL, R.G. 1985. Growth, sexual maturity and reproductive output. Crust. Issues 3: 101-128.

Hebling, N.J. \& W. Rodrigues. 1977. Sobre uma nova espécie brasileira do gênero Aegla Leach, 1820 (Decapoda, Anomura). Papéis Avuls Zool., São Paulo, 30 (19): 289-294.

JoHN, P.H. 1978. Discharge measurements in lower streams. Internat. Rev. Gesam. Hydrobiol. 63 (6): 731-755.

López, M.T. 1965. Estudios biológicos en Aegla odebrechtii paulensis Schmitt. Bol. Fac. Filos. Ciênc. Univ. São Paulo 287 (25): 301-314.

López, M.T. \& P. Sawaya. 1960. Observaciones biológicas en la población de Aegla odebrechtii paulensis, Schmitt de Alto da Serra, São Paulo. An. Acad. Bras. Ciênc. 32 (2): 37-38.

MAACK, R. 1968. Geografia física do Estado do Paraná. Curitiba, CODEPAR, 350p.

MAIER, M.H. 1978. Considerações sobre características limnológicas de ambientes lóticos. Bol. Inst. 
Pesca, São Paulo, 5 (2): 75-90.

Mouchet, S. 1932. Notes sur la biologie du galanthéide Aeglea laevis (Latr.). Bull. Soc. Zool. Fr., Paris, 57 (59): 316-340.

ODUM, E.P. 1971. Fundamentals of Ecology. Philadelphia, Saunders, 574p.

Oliveira, E. \& S. MAsunARI. 1995. Estrutura populacional de Petrolisthes armatus (Gibbes) (Decapoda, Anomura, Porcellanidae) da Ilha do Farol, Matinhos, Paraná, Brasil. Revta bras. Zool. 12 (2): 355-371.

Rodrigues, W. \& N.J. Hebling. 1978. Estudos biológicos em Aegla perobae Hebling \& Rodrigues, 1977 (Decapoda, Anomura). Rev. Brasil. Biol. 38 (2): 383-390.

SCHÄFER, A. 1985. Fundamentos de ecologia e biogeografia das águas continentais. Porto Alegre, Ed. UFRGS, 532p.

SCHMITT, W.L. 1942. The species of Aegla, endemic South American freshwater crustaceans. Proc. U.S. Nat. Mus. 91 (3132): 431-524.

SiEgEL, S. 1981. Estatística não paramétrica para as ciências do comportamento. São Paulo, Ed. McGraw-Hill, 350p.

Swiech-Ayoub, B.P. \& S. Masunari. 2001. Biologia reprodutiva de Aegla castro Schmitt, 1942 (Crustacea, Anomura, Aeglidae) no Buraco do Padre, Ponta Grossa, Paraná, Brasil. Revta bras. Zool. 18 (3): 1019-1030.

Recebido em 28.XII.2000; aceito em 28.VIII.2001. 